\title{
LA-UR-96- 4842
}

$$
1 A-4 R--96-4842
$$

TITLE: NATIONAL LABORATORIES' CAPABILITIES SUMMARIES FOR THE DOE VIRTUAL CENTER FOR MULTIPHASE DYNAMICS (VCMD)

AUTHOR(S): $\quad$ Edward L. Joyce, ET-PO

RECEIVED

FEB 141997

OSTI

This report was prepared as an account of work sponsored by an agency of the United States Government. Neither the United States Government nor any agency thereof, nor any of their employees, makes any warranty, express or implied, or assumes any legal liability or responsibility for the accuracy, completeness, or usefulness of any information, apparatus, product, or process disclosed, or represents that its use would not infringe privately owned rights. Reference herein to any specific commercial product, process, or service by trade name, trademark, manufacturer, or otherwise does not necessarily constitute or imply its endorsement, recommendation, or favoring by the United States Government or any agency thereof. The views and opinions of authors expressed herein do not necessarily state or reflect those of the United States Government or any agency thereof.

By acceptance of this article, the publisher recognizes that the U.S. Government retains a nonexclusive, royalty-free license to publish or reproduce the published form of this contribution, or to allow others to do so, for U.S. Government purposes.

The Los Alamos National Laboratory requests that the publisher identify this article as work performed under the auspices of the U.S. Department of Energy.

\section{DSTREITON OF THS DONUNT IS UNIMUTED}
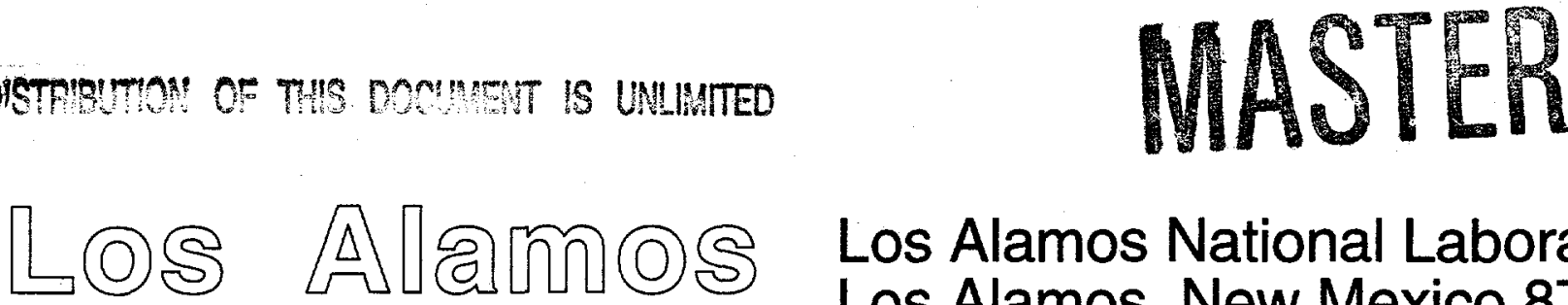

\section{Los Alamos National Laboratory Los Alamos, New Mexico 87545}


NATIONAL LABORATORIES' CAPABILITIES SUMMARIES FOR THE DOE VIRTUAL CENTER FOR MULTIPHASE DYNAMICS (VCMD)

\author{
FINAL DRAFT \\ DO NOT CITE \\ December 2, 1996
}




\section{CONTENTS}

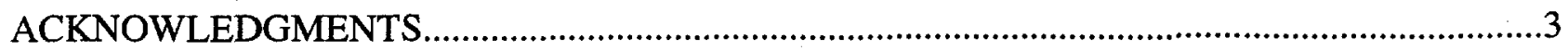

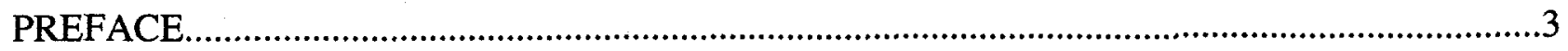

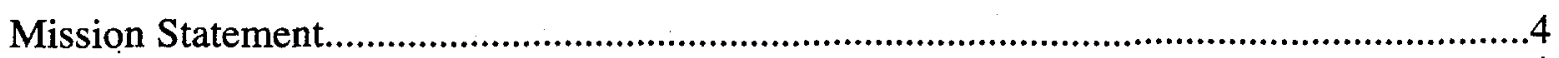

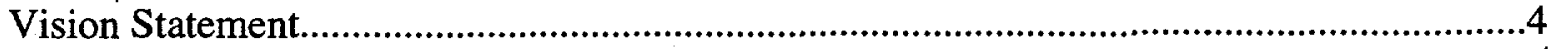

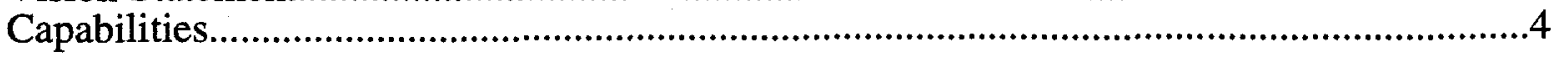

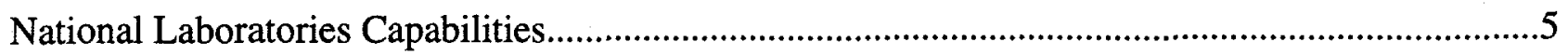

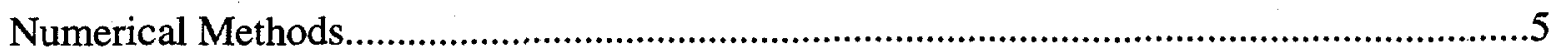

Phenomenology and Constitutive Theory and Modeling.................................................16

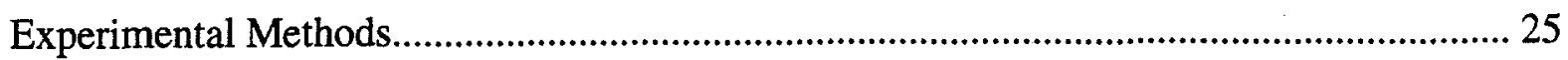

36

Applications.

APPENDIX A: Representatives and Alternates for the Multiphase Technology Center. 
The contributors from each of the government owned government contracted (GOCO) National Laboratories and government owned government operated (GOGO) Energy Centers (hereinafter referred to as National Laboratories or Laboratories) have obtained or are proceeding to obtain official security and patent clearances.

\section{ACKNOWLEDGMENTS}

The members of the Virtual Technology Center would like to acknowledge the generous support of Ms. Denise F. Swink and Dr. Brian G. Volintine of the US Department of Energy (DOE), Office of Industrial Technology (OIT) for financial support to prepare this capabilities document report. They would also like to thank Dr. Robert W. Lyczkowski of Argonne National Laboratory who assisted in the compilation of this document, as well as the generous assistance given by the contributors of the various sections whose names are listed in Appendix B. Without their cooperation, this document would have been virtually impossible to assemble.

\section{PREFACE}

Pursuant to our responsibilities of preparing a more complete Laboratories capabilities statement, and to obtain a concise document for circulation to possible sponsors of the proposed virtual technology center, each Laboratory has compiled the relevant information on their expertise. To expedite the process, the Laboratory representatives reviewed the four capabilitiy categories decided upon at the February. 21, 1996 Washington, DC meeting and provided a single sheet for each in the following format (Note: Not all Laboratories have contributions for all four capabilities.

$* * * * * * * * * * * * * * * * * * * * * * * * * * * * * * * * * * * * * * * * * * * * * * * * * * * * * * * * * * * * * * * * * * * * * * * * * * * * * *$

Capability: (e.g., Numerical methods for multiphase flow)

Estimated Number of Professionals: (Cite the number of people either working on current projects, or on projects that have been concluded within the past 3 years and whose expertise could be made available to the field again.)

Sponsors: (e.g., DP, EE, EM, WFO, NRC, ...)

Description: (A descriptive narrative not to exceed a single sheet total for each capability assuming 12 point Times font.)

$* * * * * * * * * * * * * * * * * * * * * * * * * * * * * * * * * * * * * * * * * * * * * * * * * * * * * * * * * * * * * * * * * * * * * * * * * * * *$

To avoid ambiguities in what is meant by multiphase dynamics and to limit the scope of activities to a reasonable focus as outlined in "Virtual National Laboratory for the Investigation of Multiphase Dynamics An Evolving Draft White Paper", P. G. Apen et al., Los Alamos National Laboratory Report LA-UR-95-2968 (September, 1995) we use the following definition in deciding what is to be included. By multiphase dynamics we mean the study of materials in motion in which the motion of one phase relative to another is of major importance, and where the material phases interpenetrate at scales small compared to the overall dimensions of the problem. While this definition is somewhat loose, it provides for a host of problems in which the material motions can be described by separate dynamical equations for each phase coupled by exchange functions for mass, momentum, and energy. Examples include (but are not limited to) multiphase stirred tank chemical reactors, fluidized beds, bubble columns, some porous media flows, and metal casting.

The compiled summaries received from the representatives listed in Appendix B have been edited into the format given above. These have not been modified significantly. 


\section{DISCLAMMER}

Portions of this document may be illegible in electronic image products. Images are produced from the best available original document. 
The following organizations attended the February 21, 1996 meeting in Washington DC: LLNL, SNL, ANL, ORNL, BNL, PNL, LBNL, LANL, METC, INEL, and DOE. (PETC was absent from this meeting). The group reviewed and agreed to the following Mission and Vision statements, as well as the list of Capabilities below for the VCMD. Each Laboratory (except LBL) submitted to ANL one page summaries for capability. One page summaries for each capability were then prepared.

\section{Mission Statement}

The VCMD integrates and develops the resources of industry, government, academia, and professional societies to enable reliable analysis in multiphase computational fluid dynamics (CFD) This will be accomplished by a focused effort to obtain a fundamental understanding which will be used to solve problems crucial to energy conversion, industrial competitiveness, environmental remediation, and National security.

\section{Vision Statement}

The VCMD will bring multiphase CFD into the realm of an enabling technology. As such, the VCMD membership will have the capability to predict with confidence the performance of various multiphase systems. The performance prediction will be comprehensive in that its impact on the environment and on resources will be discernible.

The primary means by which the VCMD focus will be maintained is by the creation, support, and validation of a computer simulation capability for multidimensional, time-dependent problems in complex multiphase flows that arise in problems important to the VCMD membership.

\section{Capabilities}

1) Numerical methods for multiphase flow.

2) Phenomenology and constitutive theory and modeling - includes: turbulence and exchange.

3) Experimental methods for multiphase flows - includes advanced diagnostics, advanced testbeds, facilities, and data bases.

4) Multiphase flow applications. 


\section{NATIONAL LABORATORIES CAPABILITIES}

\section{Numerical Methods}

Solution of the most difficult scientific and technical problems involving multiphase fluid dynamics is driven by specific technological applications. While the computational tools used may be common to many problems, each specific application has its particular flow geometry, number and type of fluid constituents, material thermodynamic properties, mixing and turbulence regimes.

Problems currently being studied require the understanding of multiphase transport of heat, fluid-gas-solid mixes, and reactive flow in a porous medium; such problems may be related to oil and gas reservoirs, or movement of pollutants through the ground. Combustion, burning, and in particular studies of internal combustion engines require detailed simulation to examine improved efficiency, homogeneity of temperature, and structural problems of the furnaces, engines, or other containers. Metal or glass processing, including casting, forging, mold filling and solidification present still more challenges. A significant capability in multi-phase flow modeling exists at the DOE labs growing out of work on gaseous diffusion, nuclear reactors, and reactor safety, as well as non-nuclear sources of energy such as coal.

Beyond the solution of the individual problems is the coupling of processes to optimize entire systems of processes. For instance, the processes in a iron furnace reactor or a particular process in a chemical plant may be modeled by one set of fluid equations. These may then be coupled to other processes, in serial or parallel, until the entire plant is modeled, enabling optimization of an entire plant. The concept has been dubbed "Refinery of the Future" by the oil and gas industry.

The range and size of problems requires computational methods that take advantage of the most advanced computers. Development of parallel machines and of parallel algorithms designed for such machines has enabled solution of problems which were heretofore impossible to solve computationally. The same statement can be made about handling of the immense amount of data generated by a detailed simulation. Distributed and shared-memory computer architectures have both emerged as the way to increase computational power. Visualization of complex 3-dimensional flows is now also practical for obtaining useful information from the solutions. Mathematical methods range from fluid approaches involving solutions of large-scale PDE systems and linear algebra systems, to combination particle-fluid systems and discrete particle systems with up to a billion particles. Advanced computational methods include finite-element and finite-volume techniques, Krylov based iterative algorithms, and Monte Carlo methods.

The development of new numerical methods must necessarily parallel the development of advanced computing platforms in order to make efficient use of them. This requires availability of these platforms to the scientists who are developing these methods. It also requires support for their development even though such development is not tied to any specific multiphase problem. Other relevant developments in data analysis and management will play an important role; their development must not be neglected. The concept of advanced computation is as open-ended as the future of computers and networks in our society. It stands to provide great payoffs to science and industry. 


\section{ANL Capability Area: Numerical Methods}

Estimated Number of Professionals: Reactor Analysis Division: 28; Reactor Engineering Division:14; Mathematics and Computer Science Division: 6

Sponsors: ER-MICS, OFA, NSF, DOE, USNRC, EPRI, private (electric utility, automotive, offroad equipment, railroad technology, seismic isolation, oil refinery)

\section{Description:}

Reactor Engineering and Reactor Analysis Divisions: Code development and Analysis of Complex Flow Systems

Multi-component, multiphase flow, Compressible and incompressible fluids, Laminar and turbulent flow, Natural and forced convection, Steady-state and transient conditions, Hydrodynamic and wave instabilities, Liquid breakup and atomization, Entrainment and deposition of gases, particles and droplets in flowing systems, Physical and chemical reactions in flowing systems

Computer Codes COMMIX Fluid flow and heat transfer analysis in multi-dimensional, multicomponent systems SWAAM A series of codes for fluid transient analyses in complex piping and heat transport systems ALICE 2-D Arbitrary-Lagrangian-Eulerian code for fluid transient and vessel response prediction under impulsive-type loads FLUSTR 3-D 33 finite element code for dynamic and seismic analyses of sloshing and hydrodynamic loads in fluid-structure systems SHAPS 3-D piping code for calculating pressure wave propagation and piping response

Mathematics and Computer Sciences Division; Numerical Methods and parallel computation

The Portable, Extensible Toolkit for Scientific Computation (PETSc) is a freely available numerical software library for the parallel (and uniprocessor) solution of large-scale systems of PDEs, including multiphase flow problems. PETSc integrates a hierarchy of modules that range from lowlevel distributed data structures for vectors and matrices through high-level nonlinear solvers. Since PETSc is carefully designed with prudent use of modern programming paradigms, the software separates issues of parallelism from choice of algorithms and enables use of a building-block approach to application construction. PETSc has been designed for and motivated by actual application problems, including CFD, oil reservoir simulation, and finite element structural problems. PETSc is usable on all contemporary workstations and MPPs in applications written in FORTRAN 77, C, and C++.

The computational challenges for multiphase flow include the coordination of detailed physical models and various algorithmic approaches. This complexity clearly demands a framework such as PETSc that provides broad-based infrastructure with provisions for easy customization and extension. By devoting strict attention to component interoperability, PETSc enables the integration of independently developed application modules, which often most naturally employ different coding styles and data structures. 


\section{BNL Capability Area: Numerical Methods}

Estimated Number of Professionals: 10

Sponsors: USNRC, DOE, ESSERCO

\section{Description:}

BNL staff has been developing multiphase flow codes for many applications. Two major areas have been system codes for USNRC and fundamental aspects of numerical methods such as the effect of non-linearity or development of algorithm for parallel computing.

We have developed a series of system codes to simulate boiling water reactor, pressurized water reactor and liquid metal breeder reactors. These codes are based on drift flux formulation. The numerical approach varies from finite difference to momentum integral methods. In the momentum integral method, the momentum equation is integrated over the flow path to reduce the partial differential equation to ordinary differential equation. Similarly mass and energy balances are integrated to obtain an ordinary differential equation for system pressure. Furthermore, the energy and mass balances are also solved for individual cells. This formulation also includes two-phase level tracking. The examples of codes based on this approach are; RAMONA-4B, HIPA-BWR and HIPA-PWR. The HIPA series of code are programmed with simulation language to provide efficient interactive capability.

The other areas are development of HFSPRAY code based on Eulerian-Lagrangian approach. In this code the gas phase is modeled with Eulerian approach while the spray models are based on Lagrangian approach. Codes are also being developed to model multiphase flow through porous media with application to a reservoir. Problems of chaotic flows due to non-linearity in the equations are also being addressed.

We have also developed LINK programs to combine two different system codes to enhance the applicability of the codes for coupled systems. We coupled RETRAN with MINET code which modeled BOP. Similarly we combined RELAP5 with CONTAIN codes using PVM code.

Codes developed: RELAP-3B, RAMONA-4B, HIPA-BWR, HIPA-PWR, SSC, MINET

etc. 
INEL Capability Area: Numerical Methods

Estimated Number of Professionals: 3 FTE

Sponsors: DOE-Advanced Industrial Concepts, Thermal Sciences Program, Advanced Two-Phase Flow Modeling Project, Heat Transfer Research, Inc., University of Colorado at Denver, INEL Long Term Research Initiative in Computational Mechanics (LDRD pool), ICASE (Dr. David Keyes)

\section{Description:}

Next-generation particle-fluid two-phase flow model with continuous liquid and gas phases, separated by a sharp interface, with entrained polydisperse discrete drops and bubbles.

Development of the first one-dimensional particle-fluid two-phase flow model with the capability to predict flow regime transitions mechanistically.

Shared memory parallel (SMP) methods for solving coupled, non-linear algebraic equations associated with modeling of advanced fluid flow/heat transfer problems.

Potential applications include energy exchange equipment (boilers, condensers, heat exchangers, steam generators, etc.), the petroleum and chemical industries, and nuclear reactor safety.

Development of a scaleable Newton-Krylov-Schwarz algorithm for SMP architectures for up to 16 processors (to date) based on a very low Mach number, fully compressible flow model problem.

Potential applications include energy exchange equipment (boilers, condensers, heat exchangers, steam generators, etc.), the petroleum and chemical industries, and nuclear reactor safety.

Extension of the algorithm to larger numbers of shared memory processors and scaleability for distributed memory architectures. 


\section{LANL Capability Area: Numerical Methods}

\section{Estimated Number of Professionals: 28}

Sponsors: DP, EM, ER, EE, FE, WFO, private funds-in.

Description: Work proceeds in this area on a number of different projects as follows. Implicit multifield computation schemes for complex geometries are being developed. Multiphase particlein-cell methods are being adapted for use in various industrial and national security applications. Lattice-Boltzmann methods are being developed for multiphase flows such as oil and gas in porous reservoir rock. Simulation methods for multiphase flow in porous media are being refined. Interface tracking methods for multiphase flows are being developed. Monte Carlo methods for spray simulations are being refined. Unstructured grid methods are being developed. The following computer codes embody many of these activities:

CFDLIB - Multifield, multimaterial, multispecies general purpose computer code library for high and low speed reactive multiphase flows with complex geometries and fluid structure interactions in 2 and 3 dimensions. Cell-centered finite volume computational scheme uses the Arbitrary Lagrangian-Eulerian method with a multiblock data structure. Allows efficient parallelization and enables the treatment of complex geometries. Lagrangian fluid-implicit-particle scheme allows simulation of mobile and fixed imbedded objects. CFDLIB has been used to simulate 2,3 and 4phase flows such as bubble columns, gas-liquid-solids ebullated bed flows, gas-solid riser flows with evaporating liquid sprays, 4-phase iron smelters with molten metal, slag, coal and supersonic gas as well as multiphase defense applications. Coarse to moderately fine grained parallel simulations of multiphase flow simulations are being performed and refined with the CFDLIB program on platforms such as the Cray T3D, IBM workstation clusters and various multiprocessor workstations. Use is made of both PVM message passing protocols and Cray's proprietary F-- protocol which takes advantage of the CRAY T3D shared memory environment.

TELLURIDE - Implicit multimaterial free surface flow code designed for mold filling and casting simulations. Highly advanced and modular FORTRAN 90 program structure with many features designed for fine-grained parallel computations. Unstructured grid data structure enables computation on intricate 3-dimensional grids. State-of-the-art interface tracking algorithm enables detailed computation of material interface motion such as gas-liquid interfaces and liquid-solid solidification fronts encountered in processes such as mold filling and casting. Coarse to very fine grained computational methods are being developed for unstructured grids in association with the TELLURIDE project. This involves new parallel gather-scatter library (PGSLib) for unstructured grids. The library is written in C language and hooks easily to F77 or F90. It is based on the MPI standard for message passing. The library has been demonstrated in the TELLURIDE code on an IBM workstation cluster. The library is very portable and easily hooked into other codes. The library allows arbitrary mesh decomposition. This paradigm enables true parallel distributed memory computations on unstructured grids. This is in contrast to other treatments wherein the entire mesh exists on each processor's memory and the calculations are multitasked. Maximum parallel efficiency is achieved on shared memory platforms. This is a first for parallel distributed memory calculations. 


\section{LLNL Capability Area: Numerical Methods}

Estimated Number of Professionals: between 10 and 50

Sponsors: DOE, OFA, DoD, private in-kind

\section{Description:}

ALE3D (Arbitrary Lagrangian Eulerian 3D Code) is a general purpose code developed at LLNL that can model coupled fluid/structure interaction with heat transfer as well as chemical reactions. It is a finite element code which treats fluid and elastic-plastic response on an unstructured grid. ALE3D is currently being applied to a number of problems involving fluid/structural dynamics, including steady state and transient flows and shock hydrodynamics. For example, ALE3D is being used to model industrial problems such as casting, forging, and extrusion, in addition to the modeling of aeropropulsion systems. It is also being used to address fire safety of explosive systems.

A new generation ALE3D code (ALEC: Arbitrary Lagrangian Eulerian C-code) is being developed for use on parallel machines. Like the serial version, it will have the ability to model fully coupled solid mechanics, heat transfer with phase change, and chemical reactions.

CALE (Arbitrary Lagrangian Eulerian 2D Code) is a two-dimensional multiphase, multi-material, finite-element arbitrary Lagrangian/Eulerian general-purpose code for fluid-structure interaction phenomena. It can accommodate high-strain rate material properties during interaction. CALE has been applied to such diverse problems as a liquid jet impinging on a solid surface and the process of bubble formation/implosion in deep underwater situations.

\section{Incompressible and Compressible Adaptive Mesh Refinement Codes}

The compressible AMR code is based on a model of two-phase turbulent flow which can account for turbulent transport and entrainment of particulates. Adaptive mesh refinement (AMR) is used to follow the convective mixing process. The code can model an explosion and account for after burn effects caused by turbulent mixing of detonation product gases with air. The incompressible AMR code solves for 3D flow in the limit of zero Mach number and can account for buoyancy effects.

\section{High-Performance Global Climate Modeling}

We are developing an advanced generation of parallel climate models. These models can simulate long- and short-wave radiation, moisture convection, simplified ozone photochemistry, cumulus convection, precipitation, and riverflow.

\section{Combustion Modeling}

LLNL has established the unique capability to model chemical kinetic systems of combustion problems related to practical combustion systems such as internal combustion engines, industrial burners, and other practical combustion devices. 


\section{ORNL Capability Area: Numerical methods}

\section{Estimated Number of Professionals: 37}

\section{Description:}

Solution methods and reusable software components for CFD and thermal convection problems.

Includes solution of linear algebraic systems as well as nonlinear systems, using both direct and iterative solution methods. Has resulted in software package for dense linear algebra systems, LAPACK, and for parallel computers, ScaLAPACK. Special techniques, such as the conjugate gradient-like method, have been developed for sparse linear systems. Development of the HEATING6 code has resulted in a variety of tools to tackle multi-phase flow problems.

Message-passing interface (MPI) implementation of PHOENIX.

This computational fluid dynamics tool is portable to a wide range of parallel machines, and enables the use of high performance computing for a diverse collection of large scale flow simulations.

Advanced and distributed computing tools and high-performance storage systems.

A number of software tools important for use of message passing parallel computers have been developed at ORNL. These include the PVM (Parallel Virtual Machine) Software, the ScaLAPACK linear algebra library for parallel computers, and DOLIB/EDONIO, a system for distributed objects on parallel computers. An 100 Terabyte UNITREE/HPSS storage system is also available to users of the ORNL Center for Computational Sciences for archiving the large volumes of model output generated by state of the art CFD calculations.

A Distributed-Memory Algorithm for Chemically Reactive Flows.

Parallel algorithm have been developed for numerical simulation of chemically reactive flows on message-passing, distributed-memory computers. These have been implemented in the combustion engine code KIVA and are being tested on the Intel Paragon.

Grand Challenge Problems in Environmental Modeling and Remediation: Groundwater Contamination Transport.

In conjunction with the PICS consortium, a 3-D parallel groundwater contaminant transport code is under development. The code incorporates complex non-ideal processes involving saturated, unsaturated, and/or multi-phase flow, and chemical, biological, and geochemical reactions. A capability for radio-nuclide decay with multiple species transport is also being developed. 
PNNL Capability Area: Numerical Methods

Estimated Number of Professionals: 6 FTE

Sponsors: DOE-EM, LDRD

\section{Description:}

Subsurface Multiphase Flow (4 FTE, DOE-EM). STOMP (subsurface transport over multiple phases) is a numerical simulator for modeling subsurface flow and transport processes in complex nonisothermal, multiple-phased, variably-saturated environments. The code employs an integrated-volume finite-difference approach for the physical domain and a backwards Euler approach for the time domain to discretize the governing partial differential conservation equations. Coupled solutions of component mass and energy conservation equations over four immiscible phases (aqueous, gas, ice, and nonaqueous liquid) are possible. Simulation of freezing conditions is currently limited to air-water systems. Solute transport problems with equilibrium partitioning between four phases (aqueous, gas, nonaqueous liquid, and solid) may be solved for multiple dilute solutes with radioactive decay. The solute transport equations are solved sequentially to the coupled flow and heat transport equations. Nonlinearities in the discretized coupled flow and heat transport equations are resolved with a Newton-Raphson iteration scheme. Phase appearances and transitions are handled through variable switching schemes. The saturation-relative permeability-pressure constitutive theory for describing both two-phase (water-air) and three-phase (wateroil-air) systems include fluid entrapment and hysteretic effects. The simulator includes a variety of boundary conditions, and allows computation domains with both permanent and dynamically defined inactive nodes. The simulator currently provides two linear system solvers, a directed banded scheme and an iterative conjugate gradient algorithm. Chemical reactions for multiphase flow fields can be treated in an uncoupled manner with a second PNNL simulator, MCTRACKER.

Parallel Port of TEMPEST Code (2 FTEs, LDRD). The TEMPEST fluid dynamics computer code solves the three-dimensional, time-dependent, equations of turbulent mass, momentum and energy transport. This code has been under continual modification and development to deal with new simulation needs. In addition to the application specific changes addressed under "Multiphase Applications", a significant numerical methods effort has been the porting of TEMPEST to parallel platforms. The implicit pressure solver at the heart of this code (LSOR/ADI) presented the most significant challenge in this port. Parallel TEMPEST has been developed over the past three years using a message passing approach. Communications packages TCGMSG or MPI are used for interprocessor communication. A non-symmetric iterative linear equation solver, BiCGStab, and a hybrid iterative Krylov solver were implemented to speed up the solution of the pressure equation and the heat equation on problems using more than one processor. Using one processor the original TEMPEST solution algorithm was more than $50 \%$ faster than the new algorithm, however the new algorithm is more scaleable. Using Argonne National Laboratory's 128 processor SP-1 we were able to achieve a speedup of more than 68 using the new algorithm on a 3-D thermal convection problem with 702000 grid points. In real terms this means that we can solve this problem 38 times faster than is currently possible using the fastest serial version on an IBM RS6000/370 workstation. On PNL's 8-processor SGI Power Challenge, we were able to achieve a speedup of 3.8 over the fastest serial version on that machine. 


\section{Sandia Capability Area: Numerical Methods}

\section{Estimated Number of Professionals: 40}

Sponsors: DOE (ER, FE, EM, DP, TTI), LDRD, DoD, CRADAs (Sematech, ICI USA, Fastcast)

Description: Strong numerical methods and model development efforts, with emphasis on implementation/use of massively parallel (MP) architectures. Major work in areas of: coating and plasma processes, metal processing, and suspension flows supporting advanced manufacturing; geohydrology and flow in porous media support current WIPP/Yucca Mountain programs and other DOE/EM initiatives. Important work elements are provided below.

\begin{tabular}{|c|c|}
\hline $\begin{array}{l}\text { Reactive Flows- } \\
\text { Plasma Systems }\end{array}$ & $\begin{array}{l}\text { Develop 2-D implicit methods for plasma reactive flows for DP components } \\
\text { and microelectronics; Develop improved MP implementation of DSMC for } \\
\text { reactive-chemical and plasma-driven reactive flows }\end{array}$ \\
\hline $\begin{array}{l}\text { Reactive Flows- } \\
\text { Deflagration/Detonation }\end{array}$ & $\begin{array}{l}\text { Develop algorithms/phenomenological models for prediction of multiphase } \\
\text { reactive flows associated with deflagration and DDT processes }\end{array}$ \\
\hline Metals Casting & $\begin{array}{l}\text { Develop parallel computing simulation to predict mold filling and solidificatiol } \\
\text { processes for metal investment casting }\end{array}$ \\
\hline Coating Processes & $\begin{array}{l}\text { Advance MP GOMA capabilities/phenomenological models for } \\
\text { metal/polymer/ceramic coatings technologies - includes liquid films w/ drying } \\
\text { and evaporation }\end{array}$ \\
\hline $\begin{array}{l}\text { Aerosol Sciences - } \\
\text { Transport \& Generation }\end{array}$ & $\begin{array}{l}\text { Develop nucleation models and MP-compatible algorithms for aerosol transpol } \\
\text { in continuum/noncontinuum environments for microelectronics fabrication } \\
\text { contamination reduction }\end{array}$ \\
\hline $\begin{array}{l}\text { Flow Through Porous } \\
\text { Media: Geohydrology } \\
\text { \& Geostatistics }\end{array}$ & $\begin{array}{l}\text { Resolve gas adsorption issues in carbon foam manufacture; Develop MP } \\
\text { simulation for flow through heterogeneous geologic porous media with } \\
\text { inclusion of geostatistics; Develop numerical tools for probabilistic predictions } \\
\text { of DNAPL locations }\end{array}$ \\
\hline Granular Flows & $\begin{array}{l}\text { Develop discrete element algorithm (DMC) coupled w/ gas flow for rock } \\
\text { blasting; Develop coupled discrete particle motion/fluid flow for modeling sani } \\
\text { production from oil wells; Granular flow model for propellants; }\end{array}$ \\
\hline Suspension Flows & $\begin{array}{l}\text { Refine Boundary Element Methods to study particle-particle interactions for } \\
\text { deducing continuum constitutive models; suspensions transport model using } \\
\text { NACHO FE code }\end{array}$ \\
\hline $\begin{array}{l}\text { Lattice-Gas Automata } \\
\text { Lattice-Boltzmann }\end{array}$ & $\begin{array}{l}\text { Develop models for transport, surface reactions, dissolution and melting at } \mathrm{Re} \\
\& \mathrm{Pe}<200 \text {; model Knudsen-Fickian transition in gaseous diffusion }\end{array}$ \\
\hline $\begin{array}{l}\text { Numerical } \\
\text { Mathematics - } \\
\text { Iterative Methods }\end{array}$ & $\begin{array}{l}\text { Develop robust, iterative preconditioned Krylov methods for reactive/ porous } \\
\text { flows. Advance MP algorithms for unstructured finite-element applications - } \\
\text { solution methods/load balancing/efficient communications }\end{array}$ \\
\hline
\end{tabular}




\section{METC Capability Area: Numerical Methods}

\section{Estimated Number of Professionals: 6}

\section{Sponsors: DOE-Fossil Energy}

Description: METC uses several codes for multiphase flow simulations and postprocessing of the computational results. These codes are used to simulate processes in support of our in-house research, projects funded by our Program Management Division, or CRADA partners.

The principle METC code is MFIX, developed in-house from a version of the LANL code K-FIX which was modified to describe fluid-particle systems by Prof. Gidaspow's group at IIT. This FORTRAN code integrates the coupled, transient 1-, 2-, or 3-D transport equations for an arbitrary number, $\mathrm{N}$, of interpenetrating phases. Either Cartesian of cylindrical coordinate systems may be selected, with a variable mesh. The primary phase is a fluid phase; the other $\mathrm{N}-1$ phases are dispersed particulate phases. The code will also integrate up to three energy equations for the temperatures of the fluid phase, one unique particulate phase, and remaining phases (These $\mathrm{N}-2$ phases are assumed to be in thermal equilibrium). Each phase may contain any number of species, in which case the appropriate species equation is also solved, fully coupled to the momentum and energy equations. A general chemistry scheme allows finite rate reactions between all phases. This has been used for simulations of coal conversion processes.

The MFIX code incorporates constitutive laws which describe interphase momentum exchange and heat transfer. The drag varies with void fraction as well as slip velocity. The granular phase stress tensor switches from a kinetic theory based formalism, for lower values of the solids loading, to frictional flow formalism, at higher loadings.

The MGAS code is a variant of MFIX which has been modified to describe fixed (or moving) beds. The granular phase is assumed to be in the creeping flow regime. It contains many of the same constitutive laws as MFIX.

METC is also cooperating with Fluent, Inc., to transfer these simulation capabilities into the FLUENT code. The present version of FLUENT already contains many of these features and additional features will be added in the next release. FLUENT is used for simulations of several gas combustion projects at METC. Commercial software from the Computer Modeling Group (Canada) is used to simulate gas reservoir production. This is used in support of projects in fracture stimulation of tight reservoirs.

METC has a Silicon Graphics Power Challenge with 6 CPUs. However, we do not use this as a parallel unit. We also have access to a Thinking Machine at West Virginia University. Although funding is doubtful, there is a joint WVU-METC proposal pending with NSF to develop a parallel version of MFIX on that machine 


\section{PETC Capability Area: Numerical Methods.}

Estimated Number of Professionals: 3

Sponsors: DOE /FE

\section{Description:}

Computational fluid dynamics codes include multi-purpose commercial codes and special-purpose software, as follows:

\section{Computational Facilities:}

Fluent CFD Code

CFD200 / PHOENICS

PCGC-2 / -3, TEACH Code on SUN4 Workstation

$\mathrm{PC}$ version

DEC-alpha system

\section{AEROSOL}

A computer code computing the population balance for chemical species undergoing phase changes (in FORTRAN).

$\mathrm{F}^{*} \mathrm{~A} \mathrm{C}^{*} \mathrm{~T}$ (Facility for the Analysis of Chemical Thermodynamics)

Used for the calculation chemical equilibria, property changes during chemical reactions, and many thermodynamic properties of multiphase system.

The software resides on the computers of McGill University and is copyrighted by Thermfact Ltd.

\section{Slurry Reactor Research}

A Computer code simulating the hydrodynamics and chemical reactions in a three-phase Bubble Column Reactors (developed at IIT and expanded at PETC) is available on a Cray supercomputer (Pittsburgh Supercomputer Center). This code uses generalized Navier-Stokes equations to solve a variety of multiphase problems. The latest computational fluid dynamics code computes gas-solid-liquid hydrodynamic parameters in surry-bubble column reactors. These are the next generation reactors for synthesis gas conversion processes to produce high quality fuel. Currently the Fischer-Tropsch kinetics into the existing hydrodynamic model is added. 


\section{Phenomenology and Constitutive Theory and Modeling}

Multiphase flow modeling requires submodels for the exchange of mass, energy and momentum at the interfaces between gases, liquids and solids, and constitutive relationships for phenomena such as turbulent and granular stress and the associated conduction of heat. These submodels are developed using detailed theoretical analyses or from the analyses of experimental data. Once developed, these submodels are used in multiphase flow simulation codes. The applicability of the codes and the uncertainty in their predictions, is assessed by validating the code with the data developed for a particular application. All the laboratories participating in Multiphase Flow CFD have, in general, capabilities in this area.

It is estimated that more than 100 professionals are engaged in work associated with phenomenology and constitutive theory and modeling for multiphase dynamics across the federal laboratory system. Work is sponsored by numerous DOE offices, DoD, USNRC and work for others. Topics of research include momentum exchange, bubble dynamics, heat transfer, turbulence, component models, granular materials, colloids, wall effects, suspensions, porous materials, viscoelasticity and chemical equilibria. Momentum exchange modeling includes such topics as the development of models for drag, lift, added mass, etc. which account for the effects multi particle interactions and clustering. Turbulence modeling efforts include large eddy simulations, direct numerical simulations, spectral modeling, particle-fluid interactions and non-linear stress. Both theoretical and experimental work is covered. Code validation includes comparison of code simulation with the experimental data from either separate effects or integral effects tests relevant to applications. Furthermore, special procedures of quantifying the uncertainty in the code prediction due to numerics and submodels of phasic interactions have also been developed. 


\section{ANL Capability Area: Phenomenology and Constitutive Theory and Modeling}

Estimated Number of Professionals: Energy Systems Division: 2; Energy Technology Division: 4; Reactor Analysis Division: 20; Reactor Engineering Division: 10,

Sponsors: DOE, USNRC, EPRI, PETC

\section{Description:}

Reactor Engineering and Reactor Analysis Divisions: : Heat Transfer Expertise

The Reactor Engineering and Analysis division have wide-ranging expertise, experience, and accomplishments in the field of heat transfer that have been developed in support of reactor safety and can be directly applied or readily adapted to many other fields. Expertise encompasses transient and steady-state analyses with all three heat transfer modes (conduction, convection, and radiation). Thermal-hydraulics capability includes forced and natural convection, laminar and turbulent flow, and multi-phase heat transfer. Problem solving ranges from understanding the fundamentals of underlying phenomena to engineering analyses of full-scale integrated systems. Areas of particular strength include thermal environments which are far off-normal or extremes.

Energy Technology Division: Development of advanced turbulence models for multiphase flows.

Because direct numerical simulation of turbulence is still limited to simple geometrical configurations and to low Reynolds numbers, alternative models must be considered for engineering applications. Among these the Large Eddy Simulation (LES) techniques, with subgrid-scale (SGS) modeling, are gaining widespread consideration, also for multiphase flows and combustion processes. Alternatively, advanced turbulence models based on Reynolds stress equations can be applied to the individual phases in multiphase flows, with interaction between the phases, for instance combustion processes.

Particles carried by a fluid can either increase the turbulence intensity or damp it, according to the particles Reynolds number. Increase of turbulence due to particles with high Reynolds number can be simulated by adding, in the equations of the turbulence model, terms which account for the additional turbulent kinetic energy produced by the particles, due to vortex shedding. Attenuation of turbulence due to particles with small Reynolds number is due to added shear produced by the particles which participate to the oscillating motion of the fluid. This effect can be simulated by computing turbulent spectra in the carrying fluid and integrating them over the full range of wavenumbers to obtain the integral turbulent kinetic energy.

\section{Energy Systems Division: Advanced Nonlinear Control}

The granular kinetics, for example, can be measured nonintrusively using acoustic shot noise excitation of the wall of fluid-solids systems. CFD software can be used to interpret these measurements more accurately and to relate them to important physical phenomena such as splash, bubble, and stagnation regions. The software would also be used to assist in the development of NOVEL instrumentation and erosion devices which measure the granular temperature (fluctuating kinetic energy). The granular temperature together with an equation of state can be used to deduce the porosity and hence the solids flow rate, velocity and volume fraction. 
BNL Capability Area: Phenomenology and Constitutive Theory and Modeling

Estimated Number of Professionals: 8

Sponsors: USNRC

\section{Description}

We have developed models of individual components and processes which are then used in the system codes. The specific models are pumps, balance of plants and control systems. We also developed models for interfacial shear, and mass transfer between the phases.

BNL has a large effort to validate computer codes. The validation process consists of three major steps. In the first step, a Phenomena Identification Ranking Table (PIRT) is prepared for each application. In the second step, for each highly ranked phenomena, suitable test data is located or obtained. Each tests is reviewed to ensure that it scales the plant for the intended phenomena. In the third step, the tests are simulated with the code and the results compared to assess the discrepancy in code models and also to make a quantitative assessment of uncertainty in code prediction of certain phenomenon. BNL has applied this approach to assess RAMONA-4B code for instability and ATWS for SBWR, HIPA-BWR for instability in BWR, TRAC code for PWR LOCA, RELAP5 for SBWR LOCA.

Code Assessed: RELAP5-3B, RAMONA-4B, HIPA-BWR, TRAC-PF1, RELAP5/MOD3 


\section{LANL Capability Area: Phenomenology and Constitutive Theory and Modeling}

\section{Estimated Number of Professionals: 11}

Sponsors: DP, ER, FE, WFO, private funds-in.

Description: Work proceeds in this area on a number of different projects as follows. Multiphase Reynolds stress transport equations are being developed. Included are the effects of interphase exchange of turbulent kinetic energy, production of turbulent kinetic energy due to slip among phases and collision effects. Also included are multiphase isotropization effects. An explicit anisotropic turbulent multiphase stress tensor is found by invoking the equilibration assumptions commonly used in single phase algebraic Reynolds stress modeling and then employing tensor integrity basis methods to invert the resulting tensor algebraic stress balances.

A spectral theory of a turbulent multiphase mixture is being developed to give insights to the effects of production, cascade and dissipation of turbulent kinetic energy at large and small length scales. Included are the effects of interpenetrating motion.

Exchange models for momentum, energy and mass transfer between fluids and particles and among particles are being developed and tested. Specific cases include packed beds, fluidized beds, bubble columns, porous media, etc. Momentum exchange effects include drag, added mass, lift, exchange stress due to mean surface pressure effects, etc.

Models for effective media in mushy zones in metal casting situations are being developed for effective specific heat, thermal conductivity and viscosity. A term similar to a D'Arcy drag is also being developed for these applications.

Work is also being done on theories of granular materials at both high and low loadings.

Fundamental multiparticle/fluid simulations are being developed and run to examine the validity of closure approximations.

Fundamentally based constitutive models for stress in multiphase mixtures at low and high Reynolds numbers are being developed and tested.

Constitutive models are being developed for granular high explosive materials. 


\section{LLNL Capability Area: Phenomenology and Constitutive Theory and Modeling}

Estimated Number of Professionals: over 20

Sponsors: DOE, DoD, private in-kind

\section{Description:}

CHEQ is a multiphase chemical equilibrium code that can model conditions that range rom atmospheric pressures to chemical explosive pressures and temperatures from cryogenic to 10,000 degrees Kelvin. CHEETAH is similar to CHEQ in that it can treat multiple phases (solid and fluid) but only one fluid phase.

Constitutive models are being developed for modeling phase change of pure metals and alloys.

The turbulence modeling varies from the traditional Reynolds-average approach ( $k-\varepsilon$ to mixinglength models) to state-of-the-art direct numerical simulation and large-eddy simulation. This work is being done in both the compressible and incompressible regimes using both finite difference and finite element methods. 


\title{
PNNL Capability Area: Phenomenology and Constitutive Theory and Modeling
}

\section{Estimated Number of Professionals: 7 FTE}

\author{
Sponsors: LDRD, DOE-EM, DOE-EE
}

\section{Description:}

Homogeneous Isotropic Turbulence Model Development (1 FTE, LDRD). The objectives of this work was to develop fundamental models and closures for particulate flows and to collect data to characterize turbulence in homogeneous particulate flows. This was accomplished by application of ensemble averaging to obtain fundamental transport equations. Experimental data was collected with LDV behind a towed grid using an index of refraction matched particle-fluid mixture.

Near Wall Effects in Pipe Flows of Complex Fluids (1 FTE, LDRD). The behavior of a concentrated suspension of solid particles flowing near a boundary is a poorly understood problem in solid-liquid two-phase flow. The rheology and turbulence characteristics of the suspension are a sensitive function of the distribution of particles and their mutual interactions. Fractionation in the boundary layer can lead to drag reduction (in the case where particles migrate away from the wall) or an apparent increase in viscosity (in the case when particles congregate near the wall). The objective of this work is to develop sufficient understanding of these near wall flows to produce boundary conditions for use in two-fluid continuum models. Experimental data was collected using conventional LDV in a slurry flow loop constructed for this effort.

Colloids ( 3 FTE, DOE/EM and LDRD). Colloidal particle interactions can have an enormous impact on processing of radioactive tank wastes. Transmission electron microscopy images reveal that over $50 \mathrm{vol} \%$ of insoluble material in Hanford tank sludge is present as crystallites that are smaller than 1 micron in diameter. Depending on the $\mathrm{pH}$ and salt concentration of the surrounding solution, these particles may flow independently of one another or may attract each other to form a porous network of particle chains, also known as a gel. Gel formation can dramatically effect solid-liquid separation processes and can make pipeline transport nearly impossible. Using our knowledge of colloidal particle interactions, numerical models are being developed to model particle sedimentation, predict gel formation, and to estimate the macroscopic physical properties of the gel once formed.

Bubble Dynamics (2 FTE, DOE-EE). The objective of this work was to determine mechanisms of bubble coalescence and breakup. Visualization of the coalescence/breakup process was conducted in an experiment for bubble pairs and planar swarms. Bubble size, fluid viscosity, and number of bubbles were varied. Dominant mechanisms were observed. 


\section{Sandia Capability Area: Phenomenology and Constitutive Theory and Modeling}

Number of Professionals: 16

Sponsors: DOE (DP, ER, FE, EM), LDRD, DoD

Description: Granular and suspension flows work involves applying simple, controlled experiments to study particle-particle and particle-fluid interactions needed for property characterization. NMR experiments provide continuum data needed for constitutive relation definition/code validation. Phenomenological studies for flow in porous and fractured media are focused on liquid permeation and NAPL transport in fractured media, and physics of multicomponent diffusion and advection. Work includes experiments/analyses with translation of phenomenology into porous flow codes. Important work elements are provided below.

\begin{tabular}{|l|l}
\hline Combustion Processes & $\begin{array}{l}\text { Studies of combustion of particulate matter (Biomass/coal) in a combusting } \\
\text { fluid mechanics environment }\end{array}$ \\
\hline Suspension Flows & $\begin{array}{l}\text { Experiments to study particle-particle interactions for deducing continuum } \\
\text { constitutive relations; NMR experiments to study transport processes for } \\
\text { Newtonian/non-Newtonian high-solids loaded suspensions }\end{array}$ \\
\hline Granular Flows & $\begin{array}{l}\text { Constitutive model development including experiments to study } \\
\text { separations/mixing issues including application of NMR; models to be } \\
\text { implemented into discrete element code (TRUBALL - U. Minn) }\end{array}$ \\
\hline $\begin{array}{l}\text { Flow in Porous } \\
\text { Materials }\end{array}$ & $\begin{array}{l}\text { Measurement of pore distribution and permeability in porous materials (filter } \\
\text { materials, ceramics, etc) }\end{array}$ \\
\hline $\begin{array}{l}\text { Flow in Porous Media; } \\
\text { Geohydrology \& }\end{array}$ & $\begin{array}{l}\text { Liquid permeation in geological media (explosively driven fracturing and } \\
\text { water-borne solute penetration); Multiphase flow/distribution of non-aqueous } \\
\text { phase liquids (NAPLs) in heterogeneous porous media (including heterogeneit: } \\
\text { characterization); Physics of 2-phase flows in single fractures; physics of } \\
\text { multicomponent diffusion and advection in porous and fractured media; } \\
\text { physics of surfactant-enhanced displacement of stimulation fluids from porous } \\
\text { media and hydraulic fractures }\end{array}$ \\
\hline $\begin{array}{l}\text { Multicomponent } \\
\text { Viscoelastic Materials }\end{array}$ & Development of viscoelastic material models for polymer flow simulations \\
\hline
\end{tabular}




\section{METC Capability Area: Phenomenology and Constitutive Theory and Modeling}

\section{Estimated Number of Professionals: 3}

\section{Sponsors: DOE-Fossil Energy}

Description: METC has focused on the development of constitutive laws for our code MFIX, which describes dense, multiphase flow. These laws include: gas/particle drag, particle/particle drag, kinetic theory of granular stress, frictional theory of granular stress, "granular temperature," heat transfer, coal chemistry. Many of these relationships are being incorporated into the FLUENT code.

The gas/particle drag law for dense flow depends on the slip velocity and the void fraction. METC has developed a representation of the law which interpolates smoothly between a velocity correlation for single particle drag and one for packed beds. It was found that for small particles, this correlation had to be corrected significantly to account for (subgrid scale) cluster formation.

For all but the densest flow, the stress in the granular phase is represented by a formulation based on the kinetic theory. A "granular temperature" is introduced to account for random particle motion. In MFIX, an algebraic relation is solved for this variable. For multiple granular phases, the equipartition of granular energy is assumed. For very dense flow, when the granular material is in enduring contact, the granular stress is represented by a frictional law, derived from soil mechanics.

Heat transfer in MFIX is described by engineering correlations for fluid-particle and particle-wall heat transfer. These laws are included in the energy equations in MFIX.

An empirical representation of coal chemistry has been incorporated into MFIX and MGAS to simulate coal conversion processes. Particle reactions include coal drying, devolatilization, tar formation, combustion and gasification. Products of these reactions react further in the gas phase. Several chemical schemes for sulfur captures have also be incorporated.

Methods of modeling fracture stimulation have also been developed to incorporate into a gas reservoir simulator. A variety of experimental results have been simulated to verify these laws. 


\section{PETC Capability Area: Phenomenology and Constitutive Theory and Modeling}

\section{Estimated Number of Professionals: 1}

Sponsors: DOE /FE

\section{Description}

Fundamental study of mixture theory, generic multicomponent flows, suspension rheology, entrained particles in turbulent fields, and granular materials).

\section{Liquid-Solid Flows}

\section{Suspension Rheology}

The suspension is modeled as a non-Newtonian fluid and the heat transfer and flow of such a suspension is studied in various practical geometries.

\section{Mixture Theory}

The mixture of liquid and solid particles is modeled using mixture theory. The interaction between the two phases are studied. Effects of material properties of the solid (granular) phase on the velocity profiles, concentration profiles, and pressure drop are studied.

\section{Gas-Liquid Flows}

\section{Negligible Interstitial Effects (Granular Flow)}

The effects of interstitial fluids are neglected and as a result we are only concerned with the flow of granular materials in practical geometries.

\section{Dense-phase Flows}

The mixture of the gas and solid particles is modeled using the mixture theory. Applications include pneumatic transport and fluidized beds.

\section{Gas / Solid Phase - dilute, turbulent}

In many engineering applications, such as swirling flows, the structure of turbulence is nonhomogeneous and anisotropic. Various turbulent models are studied using an established CFD code (such as FLUENT) while investigating the effects of geometry, boundary conditions, and different interaction mechanisms 


\section{Experimental Methods}

This section describes specialized laboratory capabilities for conducting experiments in multiphase flows. These include advanced diagnostics and procedures, unique instruments and specialized testbeds and test facilities.

Examples of advanced diagnostics and procedures include Particle Image Velocimetry (PIV) for instantaneous mapping of flow fields and Laser Phosphor Thermometry for measuring combustion chamber temperatures. Examples of unique instruments include the Dual-Energy Gamma system for measuring multiphase flow parameters in the subsurface. A number of advanced testbeds and test facilities are included ranging from explosion test cells for energetic materials. Flow visualization techniques are well represented and include X-Ray, ultrasonic and optical devices.

Databases resulting from tests in these facilities are highlighted in this section. 


\section{ANL Capability Area: Experimental Methods}

Estimated Number of Professionals: Energy Systems Division: 2; Energy Technology Division: 5; Reactor Analysis Division: 18 ; Reactor Engineering Division: 15;

Sponsors: DOE: (1) Office of Basic Energy Sciences (a three-year program,); (2) Office of Energy Efficiency and Renewable Energy (Thermal Science Research Program,); and (3) CRADAs - Energy Research-Lab Technology Transfer sponsored CRADAs with Modine Manufacturing Company EPRI - Nuclear Energy Division (a two-year program,)

\section{Description:}

\section{Reactor Engineering And Analysis Divisions}

High-energy containment cell capable of accommodating an explosion energy equivalent to $50 \mathrm{~kg}$ of TNT Large walk-in hood connected to a scrubber (which can handle radioactive materials) Blastresistant reaction chamber connected to a scrubber (which can handle radioactive materials) Aerosol diagnostics system Explosion containment chamber capable of accommodating an explosion energy equivalent to $1 \mathrm{~kg}$ of TNT High-speed photographic equipment including a motion picture camera with rates up to 200,000 pictures per second Flash X-ray system, single-shot as well as cine, with framing rates up to 250 pictures per second

Data acquisition systems with emphasis on high-speed data taking High-temperature (2800 deg-C) furnace with a 6" high x 3" diameter uniform temperature zone. Liquid sodium facility including glove boxes and a sodium burn cell.

Energy Technology Division:

(1) Flow-Induced Vibration Test Facility - 8000-gpm and 500-gpm water loops with air injection capability and a test section for air-water flow across a tube bundle ; (2) Flow and Heat Transfer Test Facility - a computer-controlled, thermal-hydraulic transient, nonisothermal, 2200-gpm water loop; (3) Test heat exchanger - 2-ft diameter and 12-ft long; (4) Compact heat exchanger test facilities: an adiabatic two-phase flow apparatus, small-channel heat transfer test apparatuses for flow boiling and condensing, and a small-channel apparatus for flow boiling visualization; and (5) Ultra-high-speed digitized video-based flow visualization - up to 12,000 pps

\section{Energy Systems Division:}

Multi-Phase Flow Field Analysis for Multi-Phase Flows: The ANL particle image velocimetry (PIV) system is equipped with unique high resolution CCD camera and YAG pulsed lasers. The PIV system is capable of experiments for flow visualization and quantitative measurements of liquid and solid phases in two or three phase flows. The measurements will give flow field data from which velocity distribution, velocity fluctuations, acceleration, gas and solid holdups, and bubble sizes can be obtained on a statistical manner. 


\section{BNL Capability Area: Experimental Methods}

\section{Estimated Number of Professionals: 5}

Sponsors: USNRC and DOE

\section{Description:}

BNL's main thrust in this area was in simulating phenomena related to sever accidents in the reactor. However, technology is transferable to other applications. The three problems addressed were, debris bed cooling, which reduces to multiphase flow through porous media, dispersion of molten metal and gas mixture in the cavities related to direct containment heating and quenching of molten jet in water where surface boiling occurred. Beside these applied programs, some basic air-water tests were conducted to study the flow regimes. 
INEL Capability Area: Experimental Methods

Estimated Number of Professionals: 30 FTE

Sponsors: USNRC, DOE, and LDRD

\section{Description:}

Basic research in measurement techniques for fluid/thermal phenomena. Facilities include a matched-index-of-refraction flow loop with $2 \mathrm{ft}$ by $2 \mathrm{ft}$ cross/test section.

Experiments in flow in porous media and environmental remediation processes.

Capability for full-size experimentation of two-phase flow processes and which may also involve hazardous materials. 


\section{LANL Capability Area: Experimental Methods}

\section{Estimated Number of Professionals: 11}

Sponsors: DP, ER, FE, WFO, private funds-in

Description: Work proceeds in this area on a number of different projects as follows.

Experimental methods are being developed to study mixing and Rayleigh-Taylor instabilities in high speed flows.

Experimental methods are being developed for measure stress behavior in suspensions and complex materials.

Numerous Plutonium recovery operations at LANL involve multiphase flows such as bubble columns and three phase sparged columns. Performance of this equipment is studied through experimentation with the aid of various diagnostic probes.

Cold flow (water) and hot flow (model metals) gravity-pour casting experiments are being performed. Advanced diagnostic techniques based on radiation extinction are being used to visualize the fluid motion in the cast. 


\section{LLNL Capab"ity Area: Experimental Methods}

Estimated Number of Professionals: over 200

Sponsors: DOE, DoD, private in-kind

\section{Description:}

\section{Experimental Methods}

Hydrotesting: Hydrotesting is used to capture the dynamics of materials at ultrahigh speeds. Images are captured by our ultrafast electro-optic camera, to show the dynamics of an explosion. During such testing, our explosives produce pressures so high that solid materials, even when not melted, flow like fluids.

Flash X-Ray (FXR): FXR is used to produce high-resolution X-ray pictures of high-density objects.

Piston: A gas-operated piston is used for impulse testing. The specimen can be thermally conditioned to match a desired environmental temperature.

High Pressure Strand Burner: The high pressure strand burner is used to determine the burn rate of energetic materials and will show evidence of multiphase burning.

\section{Facilities}

EMC: Energetic Materials Center

The Energetic Materials Center is a joint effort between Lawrence Livermore and Sandia National Laboratories. It has a staff of more than 200 scientists and engineers with proven expertise in high explosives, propellants, and pyrotechnics. Among its resources are several gun tubes, explosive firing tanks and bunkers, a shock tube, and a variety of the latest optical, electrical, and radiographic diagnostics.

Safety Test Facilities (Site 300)

The safety test facilities can be used to simulate arctic-to-desert conditions. For example, we can simulate accidents, ranging from handling drops to aircraft and car crashes to fuel fires. 


\section{ORNL Capability Area: Experimental Methods}

\section{Estimated Number of Professionals: 8}

\section{Description:}

Analysis of Combustion Dynamics and Engine Systems.

Using four completely instrumented engine test cells, a bench-scale packed bed reactor facility, extensive instrumentation for off and on-line exhaust gas and fuel chemical analysis, a spark- ignition engine with optical access for laser phosphor thermometry and fluorescence spectrometry, a spark-ignition engine with special ports for in-cylinder injection of uv and microwave radiation, a pulsed combustion test facility, a bench-scale fluidization models, computer controlled high-speed data acquisition and signal conditioning system, KIVA-3 engine simulator model, in-house models for simulation of nonlinear combustion dynamics and time-average engine performance, and specialized simulation models for fluidized bed combustion, we have developed and demonstrated of adaptive chaos control strategies for fluidization and pulsed combustion; demonstrated laser phosphor thermometry to measure critical component temperatures in operating engine; demonstrated fluorescence spectrometry to detect fuel in oil, injected of microwaves into spark-ignition engine cylinder at times previously achieved levels; identified of new mechanism for in-cylinder NOx formation; developed new low-NOx diesel fuel formulations; and identified prior-cycle effects in engine cyclic dispersion as having low-dimensional chaotic structure. This work included formation of extensive data bases of dynamic and time average measurements from combustion and engine experiments. Future plans include increased data acquisition and computational capabilities in the experimental test areas; increased data storage capabilities; and improved on-line engine control hardware. 


\section{PNNL Capability Area: Experimental Methods}

\section{Estimated Number of Professionals: 9 FTE}

\section{Sponsors: LDRD, DOE-EM}

Dual-Energy Gamma Radiation (1 FTE, DOE-EM). The dual-energy gamma radiation system is used to measure multiphase flow parameters for use in subsurface flow simulations. It can be used to simultaneously determine either the dry bulk density of a porous medium and the volumetric content of one fluid, the volumetric contents of two fluids, or the salt concentration and volumetric water content.

Rheometry (2 FTE, DOE-EM). A variety of instruments are used for characterization of samples, including radioactive tank wastes and non-radioactive simulant mixtures. In addition to conventional viscometry, instruments are also available for dynamic measurements under conditions of controlled stress and controlled strain. Dynamic measurement of normal stress is also performed.

Colloids Characterization (3 FTE, DOE-EM). A wide array of instruments are used for characterization of colloidal particles and agglomerates. These include devices for measurement of aggregate size, Zeta potential, Van der Waals force, bound water content, and surface tension. Facilities for both radioactive and non-radioactive are available.

Planar Ultrasonic Imaging of Opaque Slurries (1 FTE, LDRD). Studying and understanding the dynamics of many solid-liquid two phase flows is limited by the fact that these mixtures are optically opaque. A PNNL developed method for real-time ultrasonic imaging (RTUIS) is being used for non-intrusive planar velocity measurement in these types of flows. This technique has a usable degree of spatial resolution with a temporal resolution much higher than other (non-optical) planar techniques.

Particle Image Velocimetry (PIV) (2 FTE, LDRD) - Particle image velocimetry is being used at PNNL to obtain detailed instantaneous velocity maps in turbulent flow fields. One application was an investigation of a circular, pseudoplastic jet submerged in the same fluid. Preparations are now being made for use of this technique to study mixing phenomena in supercritical fluids. 


\section{Sandia Capability Area: Experimental Methods}

\section{Number of Professionals: 33}

Sponsors: DOE (OTT, FE, EM, DP, TTI), LDRD, ARPA, CRADA (Sematech)

Primary Activities: Noninvasive optical diagnostics are in development supporting DOE/ER combustion programs and aerosol projects with Sematech. Gamma and electrical impedance tomography, and electrical impedance probes are in development for probing opaque multiphase flows. Geohydrology/porous media flow studies focus on flash x-ray image analyses. Testbeds: Sandia has a wide range of laboratory-scale facilities. Our large-scale capabilities include: industrial-scale bubble column, CRF combustor systems, and the SNL Field Infiltration testbed. Support facilities such as Lovelace Research and Lovelace ITRI also support multiphase flow characterization efforts under contract. Details on specific work elements are provided below.

\begin{tabular}{|c|c|}
\hline Combustion Processes & $\begin{array}{l}\text { Combustion Research Facility - large combustor systems, diesel and internal } \\
\text { combustion engines, and other advanced testbeds for diagnostics development } \\
\text { focus on advanced optical diagnostics and chemical species characterization. }\end{array}$ \\
\hline $\begin{array}{l}\text { Suspension Flows \& } \\
\text { Granular Flows }\end{array}$ & $\begin{array}{l}\text { Small-scale labs with suspension rheology testbeds as well as access to } \\
\text { Lovelace NMR facility - Lovelace on-contract to collaborate with SNL } \\
\text { researchers. Experiments at Lovelace study particle-particle interactions for } \\
\text { deducing continuum constitutive relations and study transport processes for } \\
\text { Newtonian/non-Newtonian high-solids loaded suspensions }\end{array}$ \\
\hline $\begin{array}{l}\text { Reactive Flows - } \\
\text { Plasma Processes }\end{array}$ & $\begin{array}{l}\text { Develop plasma, optical, and laser diagnostics for measurement of spatial } \\
\text { profiles of reactive plasma-driven flow composition. }\end{array}$ \\
\hline $\begin{array}{l}\text { Aerosol Sciences \& } \\
\text { Spray Technology }\end{array}$ & $\begin{array}{l}\text { Study aerosol transport/generation in reacting flows; Develop non-invasive } \\
\text { diagnostics and collection techniques for aerosols in low pressure environment: } \\
\text { using semiconductor GEC Cell testbed; used to study effects of continuum/non } \\
\text { continuum pressure environments, plasma and neutral fields, and for seeding } \\
\text { and extraction techniques. Apply optical noninvasive measurement techniques } \\
\text { for solid/liquid spray droplet size distributions, velocity, and concentration }\end{array}$ \\
\hline $\begin{array}{l}\text { Slurry-Phase Bubbly } \\
\text { Flows }\end{array}$ & $\begin{array}{l}\text { Develop noninvasive and probe diagnostics for characterizing multi- } \\
\text { component, opaque multiphase flows; diagnostics studied: gamma and } \\
\text { electrical impedance tomography and pressure transducers for gas hold-up. } \\
\text { Testbeds: Small-scale bubble-columns/flow loops and Large-scale industrial- } \\
\text { scale testbed ( } 2 \text {-ft. dia/9-ft. tall column) for multiphase slurry bubble processes } \\
\text { Capabilities: system can be pressurized and heated; access for probes and flow } \\
\text { visualization; can use nitrogen or compressed gases, water or organic liquids, } \\
\text { and solids. }\end{array}$ \\
\hline $\begin{array}{l}\text { Flow in Porous } \\
\text { Media; Geohydrology } \\
\text { \& Geostatistics }\end{array}$ & $\begin{array}{l}\text { Implementing and refining diagnostics (flash } \mathrm{x} \text {-rays) and visualization } \\
\text { techniques (with image processing) for dense non-aqueous phase liquid flow at } \\
\text { the pore scale in heterogeneous systems. Testbed: Field infiltration test used } \\
\text { for studying phenomena and scaling of infiltration in heterogeneous porous } \\
\text { media. }\end{array}$ \\
\hline
\end{tabular}




\section{METC Capability Area: Experimental Methods}

\section{Estimated Number of Professionals: 1}

\section{Sponsors: DOE-Fossil Energy}

Description: METC has two unique instruments for measuring properties of dense phase flow systems. Both of these units were developed over the past 5 years, but have not been operated for several years.

A capacitance imaging system has been developed to capture real-time images of the void fraction as a function of time. This apparatus, which is restricted to non-conducting equipment, rapidly records the time-varying capacitance of the imaging zone for a variety of electrode activations, which are scanned rapidly. The data is stored and post-processed to determine the 3-D void fraction, as a function of

time.

A separate apparatus was developed at the University of Illinois, under contract to DOE-METC. This is a Radioactive Particle Tracking Device. A tagged particle is released in the fluidized bed and an array of counters is able to determine its location as a function of time. Thus, the trajectory of the particle can be determined. 


\section{PETC Capability Area: Experimental methods}

\section{Approximate Number of Professionals: 3}

\section{Sponsors: DOE /FE}

\section{Description:}

\section{Slurry Reactor Laboratory}

The Slurry Reactor Laboratory is a test facility to study fluidized beds and bubble column behavior at elevated pressures and temperatures. A transparent acrylic column reactor allows advanced analyses of the bubble sizes, distribution and velocities. The diagnostic and Analytical Tools include a hot-wire Anemometer and an Ultrasonic Diagnostic System.

\section{Rheology Laboratory}

Facility to study the rheological properties of a wide range of multiphase systems, e.g. slurries containing up to $40 \%$ solids, high viscosity liquids, polymers, rubber, and mixtures of these in continuous operation. Gas/solids as well as liquid/solid mixtures can be investigated under various conditions and at elevated pressures. It consists of a number of test loops for pneumatic and slurry transports at elevated pressures, and of a high temperature pumping system capable of pumping oil/solids slurries with high viscosity (up to $500,000 \mathrm{cP}$ ). A number of advanced rheometers are available. An extensional rheometer for coal slurries has been designed and successfully applied.

\section{Rheological Database:}

Extensive collection of test data for the design and operation of industrial pneumatic transport systems. 


\section{Applications}

Many applications of multiphase computational tools, and related experimental research efforts, stem from the National Laboratories' historical role in the nuclear power and defense industry and the Technology Centers' role in fossil fuel conversion technology. However, due to the generality of these modeling and experimental capabilities, current applications range far beyond these historical areas. There is still significant activity in the analysis of reactor performance and safety. Many labs are studying reactor transients, instabilities, and severe accident scenarios. Some of these applications relate to facilities in Eastern Europe. These calculations require reliable submodels for interfacial mass, momentum, and heat transfer. Such calculations describe boilers, condensers, and heat exchangers, which are important in addressing many industrial situations.

Multiphase applications of industrial interest involve materials manufacturing, with emphasis on metals processing such as welding, casting, extrusion, and forging. Sophisticated phase transition models are used to described solidification and segregation due to physical effects associated with phase transitions in alloys. Using these advanced computational tools, the fluid fill in, e.g., a casting process is simulated as well as fluid-structure interactions and chemical reactions. Multiphase flow models inherently have uncertainty due to the stochastic nature of the flow and the resulting uncertainty in the constitutive relationships. The issue of applicability and uncertainty analysis in using these codes is being addressed by laboratory researchers.

Efforts at several laboratories are examining catalytic reactor performance in the chemical and energy industry, e.g., petroleum cracking in circulating fluidized bed reactors. These applications involve multiphase (gas-liquid-solid) flow, heat transfer, and chemical transformations. The multiphase hydrodynamics determines the contacting between the reactants and/or a catalyst. Thus, reactor performance is strongly affected by the detailed structure of the flow pattern This simulation technology is also being used to analyze catalytic processing of alternative fuel feedstocks, such as biomass. Several laboratories have simulated bubble column performance.

A large effort is being mounted to simulate the behavior of the radioactive waste storage tanks at Hanford. The models describe mixing of dense liquid-particle systems, with chemical transformations, heat transfer, and phase transitions. Aside from the crucial issue of radioactivity, these processes are common to many, more conventional, chemical plants. In addition, a related capability is being used to analyze in situ vitrification of buried, radioactive waste.

Many laboratories have facilities for multiphase combustion studies. These range from spray injection in internal combustion engines to coal combustion in circulating fluidized beds. Capabilities exist to simulate turbulent, multiphase combustion of oil and coal, and to track the fate of pollutants and ash material. Many of these modeling capabilities have been applied to related commercial processes or to study environmental issues. These include spray coating, plasma sprays, and deposition studies. Similar ideas have been applied to study dispersal of particulate material in the atmosphere.

Simulations of flow through porous media have applications in many areas. Reservoir studies are important for the gas/oil industry. This same capability is applicable to ground water studies, for example, to determine the fate of a pollutant. 


\section{ANL Capability Area: Applications}

Estimated Number of Professionals: Energy Systems Division: 5; Energy Technology Division: 5; Reactor Analysis Division: 16; Reactor Engineering Division: 8

Sponsors: DOE, USNRC, EPRI, CRADA (Chevron, UOP, Caterpillar)

\section{Description}

Because of the dispersed nature of ANL's CFD activity, it is useful to group programs and projects in multiphase flow modeling in historical and sponsor-defined categories. The major groupings would involve reactor-related programs, fossil energy and conservation, projects for specific industry segments, and a broad category of work either close to the basic sciences or of extreme specialization.

ANL has multiphase simulation work in a number of specialized areas. There are extensive efforts in computational chemistry; however, these are at a quite basic level and not easily applied to engineering problems. Similarly, there is work on climate modeling, molecular dynamics, flow and diffusion in porous media, etc.

Argonne's long history in reactor research and development generated several families of codes that have multiphase capability. The most general of these is the COMMIX code series which is a threedimensional, porous-media formulation CFD code originally developed for NRC projects and later applied to a wide variety of other energy systems. A multiphase version, COMMIX-M, has been applied to slurry flows and, at present, is being used in studies of evaporative cooling. The LEVITATE and SAS4A codes are more specific to reactor applications and to severe accident analysis. For example, LEVITATE is a multiphase multicomponent code able to model and evaluate geometries that evolve in time due to local freezing and melting of components.

The general area of fossil energy systems and interest in energy conservation has led to several multiphase groups, FLUFIX 2D and 3D and the ICRKFLO codes being particular examples. These often vary in capability by what platform they run on, by whether the applications are design studies or detailed modeling of existing systems, etc. Using the 2D version of ICRKFLO as an example, it will run on a high-end PC, model integral combustion, turbulence, particle melting and evaporation, and inter-phase energy and momentum transfer controlled by interface properties. Argonne has also developed numerous multiphase simulation codes that are application specific. For example, the 2D and $3 \mathrm{D}$ casting process simulator (CaPS) has models for solidification and segregation due to physical effects associated with phase transitions in alloys. The SWAAM codes are CFD models of the system effects generated by rapid liquid metal/water reactions e.g., pressure pulse propagation, fluid/structure interactions.

Argonne has also developed numerous multiphase simulation codes that are application specific. For example, the two- and three-dimensional casting process simulator (CaPS) has models for solidification and segregation due to physical effects associated with phase transitions in alloys. The 
SWAAM codes are CFD models of the system effects generated by rapid liquid metal/water reactions e.g., pressure pulse propagation, fluid/structure interactions. 


\section{BNL Capability Area: Applications}

\section{Estimated Number of Professionals: 10}

Sponsors: USNRC, and DOE

\section{Description:}

BNL has a large program to analyze reactor transients. We are analyzing instabilities and ATWS issues for Simplified Boiling Water Reactor with RAMONA-4B code. The accuracy of prediction depends upon the models for drift flux, vapor generation, two phase multipliers and numerics. The Loss of Coolant Accidents (LOCA) for SBWR is being analyzed with RELAP5 code. The interfacial mass and momentum transfer, wall heat and momentum transfer, and the effects of noncondensable are crucial in predicting the transient. We are also analyzing VVER-440 and RMBK power plants for eastern Europe for DOE. The HIPA codes are being used by industry to analyze plant transients. The other area where we are applying codes is in severe accidents where we are applying MELCOR code.

Beside power plants, we have analyzed PUMA test facility to guide in performing the tests. The other facility which was modeled and simulated is BNL's research reactor, HFBR.

The multiphase flow codes inherently have large uncertainty due to the stochastic nature of the flow and resulting uncertainty in the constitutive relationships. The prediction must come with a statement of uncertainty. We developed a method of combining uncertainties from different constitutive relationships and their propagation during the transient. The method developed for USNRC is called Code Scaling, Applicability and Uncertainty Analysis ( CSAU) and the method is general enough to be applied to any code. 
INEL Capability Area: Applications

Estimated Number of Professionals: 100 FTE

Sponsors: US Nuclear Regulatory Commission, CRADA.

\section{Description:}

Development of advanced nuclear reactor systems modeling code with severe accident simulation capabilities.

Applications include energy exchange equipment (boilers, condensers, heat exchangers, steam generators, etc.), the petroleum and chemical industries, and nuclear reactor safety.

Copyrights: RELAP5 (in part) 


\section{LANL Capability Area: Applications}

\section{Estimated Number of Professionals: 19}

Sponsors: DP, ER, FE, WFO, private funds-in.

Description: Work proceeds in this area on a number of different projects as follows.

Multiple co-operative research efforts with private companies and internal customers cover the development of advanced computer simulation of the multiphase flow in the following applications:

- 3-phase liquid-gas-solid ebullated bed reactors for resid hydrocracking in petroleum refining

- 3-phase gas-solid-liquid riser reactors for petroleum refining

- Gas-solid riser reactors for chemical manufacturing

- Gas-solid flows in consumer products manufacturing

- 3-phase bubble columns and draft tube mixers

- Molten metal bubble column reactors for hazardous waste disposal

- Dense granular flows for the manufacture of engine block sand casts

- Powder metallurgy

- Rocket motors

- Magneto-hydrodynamics

- Metal casting

- Combustion chamber flow

- Petroleum reservoir flow 


\section{LLNL Capability Area: Applications}

Estimated Number of Professionals: over 50

Sponsors: DOE, DoD, private in-kind

\section{Description:}

The multiphase flow applications at LLNL range from defense applications to those of industrial interest. For example, there are several applications involving materials manufacturing, such as, the casting of metals and resin transport molding.

Other examples are related to environmental applications. For example, the modeling of particulate transport or pollutant dispersion for geophysical applications or the modeling of precipitation and pollution dispersion in atmospheric or climate modeling. 


\section{ORNL Capability Area: Applications}

\section{Estimated Number of Professionals: 20}

\section{Description:}

Groundwater Contaminant Transport and Flow through Porous Media.

Analysis of 3-D transport of reactive contaminants through a porous media can be used in site characterization, in the development of remediation strategies, and as a research tool to extend the understanding of complex interactions between biota, chemical reaction and underground transport. Because of the wealth of quantitative data from the continuous monitoring of Waste Area Group (WAG6), ORNL has unique facilities for validation of computer models of groundwater flow. Simulations of WAG6 remediation scenarios using the code suite FEM Water/FEM Waste on the Intel Paragon parallel computer, along with 3D Rendering/Visualization systems to aid in the analysis of the data has yielded important insights. Future emphasis will be on rapid prototyping of site specific models and improvements to transport algorithms on parallel computers.

Solid-Liquid Phase Change Modeling with Transport; Laser Target Studies.

Coupled heat and mass transport of materials undergoing complex phase transitions is central to this capability. Thermal, hydrodynamics, gas dynamics, Monte Carlo and molecular dynamics models of laser ablation processes for thin film deposition of materials have been used in conjunction with experiments by ORNL's Solid State Physics Division. Capabilities include 1D and 2D thermal phase transition models of laser-target interactions; 1D to 3D particle hydrodynamic, continuum gas dynamic, Direct Simulation Monte Carlo models of laser-ablated plume/ambient gas interactions; 3D molecular dynamics models of plume/deposition substrate interactions. Engineering application areas include latent heat energy storage systems, laser processing of silicon (annealing and ablation), and environmental remediation with In Situ Vitrification.

Advanced turbine design for ecologically friendly power stations.

Generation of hydroelectric power results in impacts on ecological systems near the power plants. Two effects are the increased temperature of the water, and the direct effect on fish which enter the turbine. Injection of air bubbles is being investigated as a possibility of mitigating these effects. Multiphase CFD calculations are used in the design of such environmentally friendly turbines. 


\section{PNNL Capability Area: Applications}

A number of significant multiphase flow applications are being addressed at PNNL. Example applications include:

Safety Analyses for Hanford Radioactive Waste Tanks (6 FTEs, DOE-EM). Hanford's radioactive waste tanks contain complex and varied mixtures of liquids and radioactive solid particulates. The settled sludge layers are chemically reactive, often gas generating and complex rheologically. The periodic release of hydrogen in potentially flammable concentrations has been a significant safety issue at the Hanford site. Over the past five years extensive changes have been made to PNNL's TEMPEST code to model fluid and thermal behavior in these tanks, in particular the response of contents to mitigation schemes such as jet mixing. The code can accommodate non-Newtonian power law fluids as well as fluids whose viscosity and yield stress depend upon solids concentration. Transport of multiple liquid, gas and/or solid species can be performed. The thermal energy solution accommodates fully coupled heat transfer in liquids, gases and solids. Equilibrium and kinetic chemistry models are the most recent addition to TEMPEST, including both dissolution and precipitation of reacting species.

Catalytic Processing of Alternate Feedstocks (3-4 FTEs, DOE-EM, EE). This and several related applications of catalytic processing are being investigated at PNNL, each using reactions at elevated temperatures and pressures in the presence of a solid catalyst. These include: 1) gasification of aqueous solutions of dissolved organics and organic solids, 2) hydrogenation of biomass fermentation products to yield polymer feedstocks, and 3) oxygenation and hydrogenation of biomass pyrolysis oils to produce lighter hydrocarbons. Multiphase flow issues include prediction of residence times for each phase.

In Situ Vitrification (ISV) of Buried Waste (6-8 FTEs, DOE-EM) Activities include pretest simulations and performance of ISV tests. Simulations are performed with PNNL's TEMPEST code which has multiple electrode multiple phase logic for Joule heating of the melt. Test data includes temperature distribution and offgas composition and flow rate. Multiphase flow issues include melt propagation and generation and volatile transport around the melt. Sites have included Hanford, ORNL and Savannah River. 


\section{Sandia Capability Area: Applications}

\section{Estimated Number of Professionals: 41}

Sponsors: DOE (DP, TTI, OTT, ER, EM),LDRD, ARPA, NRC, CRADAs (Sematech, Goodyear, Intel, GM, Reliance Electric, NCMS)

Description: Sandia applications work supports DOE DP and Energy \& Environment, industry, and other federal agencies. Manufacturing emphases are on metals processing (welding, casting, refining), spray technologies for coatings, encapsulation, and microelectronics fabrication. Longstanding applications programs are in engine combustion processes and nuclear reactor safety. Liquid phase heat transfer are tied to industrial cooling problems. Activities in flow in porous media emphasize site studies for WIPP and Yucca Mountain. Important work elements are provided below.

\begin{tabular}{|c|c|}
\hline Combustion Processes & $\begin{array}{l}\text { Experimental and modeling effort for fuel injection for diesel and internal } \\
\text { combustion engines and associated spray-droplet combustion (modeled w/ } \\
\text { KIVA). }\end{array}$ \\
\hline $\begin{array}{l}\text { Energetic Processes - } \\
\text { Melt/steam interactions }\end{array}$ & $\begin{array}{l}\text { Experiments and modeling of direct containment heating due to high pressure } \\
\text { melt ejection }\end{array}$ \\
\hline $\begin{array}{l}\text { Reactive Flows - } \\
\text { Plasma Systems }\end{array}$ & $\begin{array}{l}\text { Apply 2-D noncontinuum (DSMC) and continuum models for reactive etch anc } \\
\text { deposition flows for neutral/plasma chemical microelectronics systems }\end{array}$ \\
\hline Metals Processing & $\begin{array}{l}\text { Develop fluid/thermal/structural models for casting processes; Develop models } \\
\text { for vacuum-arc and electro-slag remelting processes for refining metals }\end{array}$ \\
\hline $\begin{array}{l}\text { Material Joining } \\
\text { Processes - Welding }\end{array}$ & $\begin{array}{l}\text { Heat transfer to molten pools and the effect upon the solid weldmets are studie } \\
\text { w/ emphasis on GTAW }\end{array}$ \\
\hline Encapsulation Processes & $\begin{array}{l}\text { Encapsulation of electronic components (Intel) and extrusion for DP } \\
\text { componentry and tires (Goodyear) - incorporation of non-Newtonian suspensic }\end{array}$ \\
\hline $\begin{array}{l}\text { Liquid Phase Heat } \\
\text { Transfer - Cryrogenics }\end{array}$ & $\begin{array}{l}\text { Liquid phase heat transfer in cooling of industrial parts - LN cooling of } \\
\text { microelectronics parts }\end{array}$ \\
\hline $\begin{array}{l}\text { Spray Processes - } \\
\text { Coatings }\end{array}$ & $\begin{array}{l}\text { Developed models for gas-liquid jet flows w/ interfacial heat transfer, chemical } \\
\text { reactions, particle drag; Droplet measurements in molten metal sprays }\end{array}$ \\
\hline $\begin{array}{l}\text { Aerosol Sciences - } \\
\text { Transport \& Generation }\end{array}$ & $\begin{array}{l}\text { Fluid-mechanical particle transfer; Analysis of particle transport/deposition in } \\
\text { microelectronic equipment for purposes of reducing particle contamination. }\end{array}$ \\
\hline $\begin{array}{l}\text { Liquid Phase Heat } \\
\text { Transfer - Cryrogenics } \\
\text { \& Heat Pipes }\end{array}$ & $\begin{array}{l}\text { 2-phase cooling and flow stability studies of cryogenic fluids in rotating frame } \\
\text { reference systems; Phenomenological models for liquid transport in porous } \\
\text { material caused by capillary pumping/evaporation }\end{array}$ \\
\hline $\begin{array}{l}\text { Flow through Porous } \\
\text { Media \& Frits; } \\
\text { Geostatistics }\end{array}$ & $\begin{array}{l}\text { Study subsurface migration of waste generated gas at WIPP; Simulate fast flox } \\
\text { mechanisms for Yucca Mtn; Simulate Thermally Enhanced Vapor Extraction } \\
\text { System and capillary barrier experiments; Model DP gas transfer system. }\end{array}$ \\
\hline $\begin{array}{l}\text { Lattice-Gas Automata } \\
\text { Lattice-Boltzmann }\end{array}$ & $\begin{array}{l}\text { Modeling solidification and extrusion of mixed viscosity melts; viscous } \\
\text { segregation of flowing immiscible liquids; contaminant transport through } \\
\text { filters/media }\end{array}$ \\
\hline
\end{tabular}




\section{METC Capability Area: Applications}

\section{Estimated Number of Professionals: 5}

\section{Sponsors: DOE-Fossil Energy}

Description: Most of METC's projects involve dense phase gas/particle flow. Obviously, a coal conversion process begins with extraction, preparation, and transportation. These operations involve solids handling on a massive scale. Usually, in these operations, the flow of the (connected) fluid can be ignored, except for the effects of changing void fraction. This aspect of the industry is not an area of experimental research at METC. However, it is at PETC.

The coal gasification projects at METC involve several process units which are (bubbling, circulating or jetting) fluidized beds or fixed beds. Their detailed analysis requires the computation of multiphase flow, including heat transfer, chemistry, and radiation.

The processes also require sulfur removal. This is usually done in a fluidized bed unit in which the sulfur is captured on a solid sorbent. A separate process unit, which also involves multiphase flow, is required for the regeneration of this sorbent material. Obviously, heat transfer and chemistry must be included to simulate these units.

Hot Gas Clean-Up projects are concerned with the removal of particulate material from a hot gas stream. The dirty gas stream is usually fairly dilute, but the particles are captured on a barrier and form an active "cake," which is a packed bed. These devices always require a back-pulse, cleaning cycle, in which the cake is dislodged. Thus, the ability to calculate the dynamics of a dense region is required. 


\section{PETC Capability Area: Applications}

\section{Estimated Number of Professionals: 4}

Sponsors: DOE /FE

\section{Description:}

Combustion and Environmental Research Facility (CERF)

A test facility to diagnose and analyze reactive multi-phase flows, consisting of a down-fired axisymmetric combustor for natural gas, pulverized coal, or slurries, used for:

Studies of turbulent flows with dispersed particle phase (liquid or solid),

Study of combustion of coal or gas,

Study of chemical transformations of ash,

Study of phase transformations of mineral matter.

Data acquisition and diagnostic capabilities:

Temperature fields, Flow Velocity fields, Particle Concentration, particle Burn-out can be monitored, and gas analyses can be performed at many points inside the radiant and convective sections.

The confirmation of the initiation of slag deposits through thermophoresis has been one of the results from this facility.

Particle Flow Analysis Facility (PFAF)

A Laboratory to simulate and measure gas or liquid flows containing small particles

The PFAF is equipped with a wind tunnel and advanced flow diagnostic tools.

Phase Doppler Anemometer:

Simultaneously measures particle size and velocity at a point.

High data rates ( $>10 \mathrm{~K}$ samples/sec) quickly generate statistical flow properties.

Particle Image Tracking System

Produces a Lagrangian measurement of particle Trajectories and velocities along trajectories through a flow field.

Double-Pulse Nd:Yag Particle Image Velocimeter

Produces an Eulerian snap-shot of a particle velocity field with high spatial resolution Pathline Flow Visualization System

A system developed at PETC to visualize streamlines and pathlines of a gas flow field.

Patents: $\quad$ Bed level monitor for fluidized or fixed granular beds $(\# 3,922,914)$

Particle Image Tracking System (\#5,333,044) 


\section{APPENDIX A}

Representatives and Alternates for the DOE Virtual Center for Multiphase Dynamics

ANL: Robert Lyczkowski Argonne National Laboratory Energy Systems Division 9700 South Cass Avenue Argonne, IL 60439-4831

Tel: $630-252-5923$

Fax: 708-252-5210

e-mail: robert_lyczkowski@qmgate.anl.gov richard_valentin@qmgate.anl.gov
Richard Valentin

Argonne National Laboratory

Energy Technology Division

9700 South Cass Avenue

Argonne, IL 60439-4842

630-252-4483

$630-252-3250$

BNL: Upendra Rohatgi

Brookhaven National Laboratory

Department of Advanced Technology

Safety and Risk Evaluation Division

Upton, NY 11973

Tel: 516-344-2475

Fax: 516-282-7650 (?)

e-mail: rohatgi@bnl.gov

INEL: Rod W. Douglass

Idaho National Engineering Laboratory

Idaho Falls, ID 83401

Tel: (208) 526-4536

Fax: (509) 526-052

e-mail: rxd@inel.gov

LANL:Edward L. Joyce

Los Alamos National Laboratory

Energy Technologies Program Office

MS D453

Los Alamos, NM 87545

Tel: (505) 665-6799

Fax: (505) 665-2964

e-mail: Joyce@lanl.gov 
T. Daniel Butler

Los Alamos National Laboratory

Theoretical Division T-3

MS B216

Los Alamos, NM 87545

Tel: (505) 667-4156

Fax: (505) 665-5956

e-mail: tdbutler@lanl.gov
Bryan (Bucky) Kashiwa

Los Alamos National Laboratory

Theoretical Division T-3

MS B216

Los Alamos, NM 87545

505-667-8812

505-665-5926

bak@lanl.gov

LBL: Karsten Pruess

Lawrence Berkeley Laboratory

Mail Stop 50E

Berkeley, CA 94720

Tel: (510) 486-6732;

Fax: (510) 486-5686

email: k_pruess@lbl.gov

LLNL: Rose C. McCallen

Lawrence Livermore National Laboratory

Center for Advanced Fluid Dynamics

Applications

Mail Stop L-170

Tel: 510-423-0958

Fax 510-422-5397

e-mail: mccallen1@1lnl.gov

ORNL:Cloyd Beasley

Oak Ridge National Laboratory

Computer Science \& Mathematics Division

MS-6359, Bldg 6025

Tel: (423)5763913

Fax: 423-576-2760

e-mail: beasleycojr@cosmail1.ctd.ornl.gov

PNL: James A. Fort

Pacific Northwest Laboratory

Environmental Technology Division

Mail Stop K7-15

PO Box 999

Richland, WA 99352

Tel: (509) 375-2300

Fax: (509) 375-3641

e-mail: ja_fort@pnl.gov email:

SNL: Arthur C Ratzel III

Sandia National Laboratories

Energetic and Multiphase Processes

Department 9112 (MS0834)

Tel: 505-844-0824

Fax 505-844-8251

e-mail: acratze@sandia.gov
Sang-Wook Kang

Lawrence Livermore National Laboratory

Thermodynamics-Fluid Mechanics Group

Mail Stop L-140

510-422-7233

510-422-5397

kang1.llnl.gov

W. Harvey Gray

Oak Ridge National Laboratory

423-574-1476

423-241-6649

whg@ornl.gov

Steven C. Weiner

Pacific Northwest Laboratory

PO Box 999

Richland WA 99352

(202) 646-7870

(202) 646-5020

sc_weiner@pnl.gov

Nancy Jackson

Sandia National Laboratories

Process Research

Department 6212 (MS0709)

505-844-0940

505-845-9500

nbjacks@sandia.gov 
METC: Thomas J. O'Brien

U. S. Department of Energy

Morgantown Energy Technology Center

PO Box 880

Morgantown, WV 26505

Tel: (304)-285-4571

Fax:(304)-285-4403

e-mail: tobrie@metc.doe.gov

PETC: Walter Fuchs

Pittsburgh Energy Technology Center

PO Box 10940

Pittsburgh, PA 15236-0940

Tel: 412-892-5745

Fax: 412-892-6204

e-mail: fuchs@petc.doe.gov

Laboratory Acronyms used:

ANL: Argonne National Laboratory

BNL: Brookhaven National Laboratory

INEL: Idaho National Engineering Laboratory

LANL: Los Alamos National Laboratory

LBL: Lawrence Berkeley Laboratory

LLNL: Lawrence Livermore National Laboratory

ORNL: Oak Ridge National Laboratory

PNL: Pacific Northwest Laboratory

SNL: Sandia National Laboratories

METC: Morgantown Energy Technology Center

PETC: Pittsburgh Energy Technology Center 